\title{
Reproductive aspects of two bythograeid crab species from hydrothermal vents in the Pacific-Antarctic Ridge
}

\author{
Ana Hilárioo ${ }^{1,2, *}$, Sara Vilar ${ }^{3}$, Marina R. Cunha ${ }^{1}$, Paul Tyler ${ }^{2}$ \\ ${ }^{1}$ CESAM, Departamento de Biologia, Universidade de Aveiro, Campus Universitário de Santiago, 3810-193 Aveiro, Portugal \\ ${ }^{2}$ National Oceanography Centre, University of Southampton, European Way, Southampton SO14 3ZH, UK \\ ${ }^{3}$ Departamento de Biologia, Universidade de Aveiro, Campus Universitário de Santiago, 3810-193 Aveiro, Portugal
}

\begin{abstract}
Bythograea laubieri, B. vrijenhoeki and alvinellid polychaetes dominate the vent fauna of the Pacific-Antarctic Ridge. We studied gonadal development in females of both crabs. They have ovary microstructures characteristic of brachyuran decapods. The ovaries are paired organs overlying the hepatopancreas beneath the carapace. Oogonia proliferate from the germinal epithelium and develop into previtellogenic oocytes that grow to $60 \mu \mathrm{m}$ before undergoing vitellogenesis. The observed maximum sizes of mature oocytes were $209 \mu \mathrm{m}$ in $B$. laubieri and $138 \mu \mathrm{m}$ in $B$. vrijenhoeki. No ovigerous females were found in the samples, which agrees with the segregation behaviour of ovigerous females away from the direct influence of the active chimney in some related species. In contrast to other species of bythograeid crabs, the oocyte size-frequency data suggest that B. laubieri and $B$. vrijenhoeki lack synchrony in reproduction of the population as a whole. Synchrony and seasonality in reproduction of $B$. thermydron have been linked to the formation of phytoplankton blooms in surface waters. We suggest that the biogeography of bythograeid crabs is determined by contrasting oceanographic regimes that influence the reproductive patterns observed in different species.
\end{abstract}

KEY WORDS: Bythograeid crab · Gonad development $\cdot$ Hydrothermal vent $\cdot$ Pacific-Antarctic Ridge

\section{INTRODUCTION}

Since the discovery of hydrothermal vents along the Galapagos Rift in 1977, an increasing number of vent sites and their communities have been described (Tunnicliffe et al. 1998, 2003). More than 500 new species of mega- and macrofauna have been identified (Desbruyères et al. 2006) and a wealth of literature on the physiology, ecology, evolution and biogeography of vent organisms has been published (e.g. Childress \& Fisher 1992, Van Dover 2000, Van Dover et al. 2002, Little \& Vrijenhoek 2003). Although the study of life histories is widely recognized as essential to understanding the ecology, population dynamics, gene flow and resulting biogeography of vent organisms, research to date has been patchy, and only a small number of species have been the subject of primarily reproductive investigations (Tyler \& Young 1999).
The family Bythograeidae, first described by Williams (1980) to accommodate Bythograea thermydron from vents in the eastern Pacific, is the only family of crabs truly endemic to deep-sea hydrothermal vents (reviewed by Martin \& Haney 2005). Recent discoveries along the southern East Pacific Rise (EPR) and Pacific-Antarctic Ridge (PAR) have revealed a greater diversity of the genus Bythograea than previously realised, and 2 new species have been described: $B$. laubieri Guinot \& Segonzac, 1997 found on vent sites between $17^{\circ} \mathrm{S}$ and $38^{\circ} \mathrm{S}$, and B. vrijenhoeki Guinot \& Hurtado, 2003 found on the PAR from $31^{\circ}$ to $38^{\circ} \mathrm{S}$. Because $B$. thermydron is the dominant crab species on most EPR vent sites between $21^{\circ} \mathrm{N}$ and $18^{\circ} \mathrm{S}$ and on the Galapagos Rift, it has been the subject of a number of ecological and physiological studies (e.g. Mickel \& Childress 1982, Bennett \& Turekian 1984, Sanders \& Childress 1985, 1992, Vetter et al. 1987, Van Dover et 
al. 1987). Several aspects of its reproductive biology, including fecundity (Van Dover et al. 1985), gametogenesis (Perovich et al. 2003) and larval development (Van Dover et al. 1984, Epifanio et al. 1999, Martin \& Dittel 2007) have also been described.

From the data available, it is apparent that the reproductive patterns of vent-associated decapods are primarily determined by phylogenetic constraints (Van Dover et al. 1985). Thus, it is expected that other species of bythograeid crabs have reproductive patterns generally similar to those of Bythograea thermydron. In this paper, we describe results from a study of the reproductive biology of $B$. laubieri and B. vrijenhoeki from the southernmost vent area known on the complex East Pacific Rise/Pacific-Antarctic Ridge. We investigated the gonadal development in female crabs of both species with the hypothesis that gametogenesis is phylogenetically constrained, and therefore characteristic of bythograeid crab species. The implications of different reproductive patterns in species dispersal and biogeography are discussed.

\section{MATERIALS AND METHODS}

Individuals of Bythograea laubieri and B. vrijenhoeki were collected on the Sebastian's Steamer vent site $\left(37^{\circ} 47.48^{\prime} \mathrm{S}, 110^{\circ} 54.85^{\prime} \mathrm{W} ; 2204 \mathrm{~m}\right.$ depth) on the Pacific-Antarctic Ridge between 21 March and 5 April 2005 during the PAR5 expedition aboard the RV 'Atlantis' (Fig. 1). This vent site is composed of 3 small mounds, up to $4 \mathrm{~m}$ high and $2 \mathrm{~m}$ wide that host several candlestick-shaped sulphide chimneys. The substratum consisted of glassy basalt with no sediment cover, suggesting that the lava emissions are very young. Using the deep-sea submersible 'Alvin', a baited trap was moored at the foot of an active sulphide edifice and retrieved after $30 \mathrm{~h}$.

Shortly after capture, all specimens were identified to species level and sexed. A total of 238 specimens were collected: 110 specimens of Bythograea laubieri and 128 of $B$. vrijenhoeki. For both species, sex ratio was estimated and differences from 1:1 ratio were analysed with a $\chi^{2}$ test.

Specimens were fixed in $4 \%$ formaldehyde for $96 \mathrm{~h}$, with changes of fixative every $24 \mathrm{~h}$, and then transferred to $70 \%$ ethanol. The carapace widths and lengths were measured to the nearest $0.05 \mathrm{~mm}$ with vernier calipers. The abdominal pleopods of each individual were examined, and all embryos found were counted and measured directly under a binocular dissecting microscope.

For the present study, 20 randomly chosen female specimens of each species were used. The entire gonad was dissected and processed for histology.

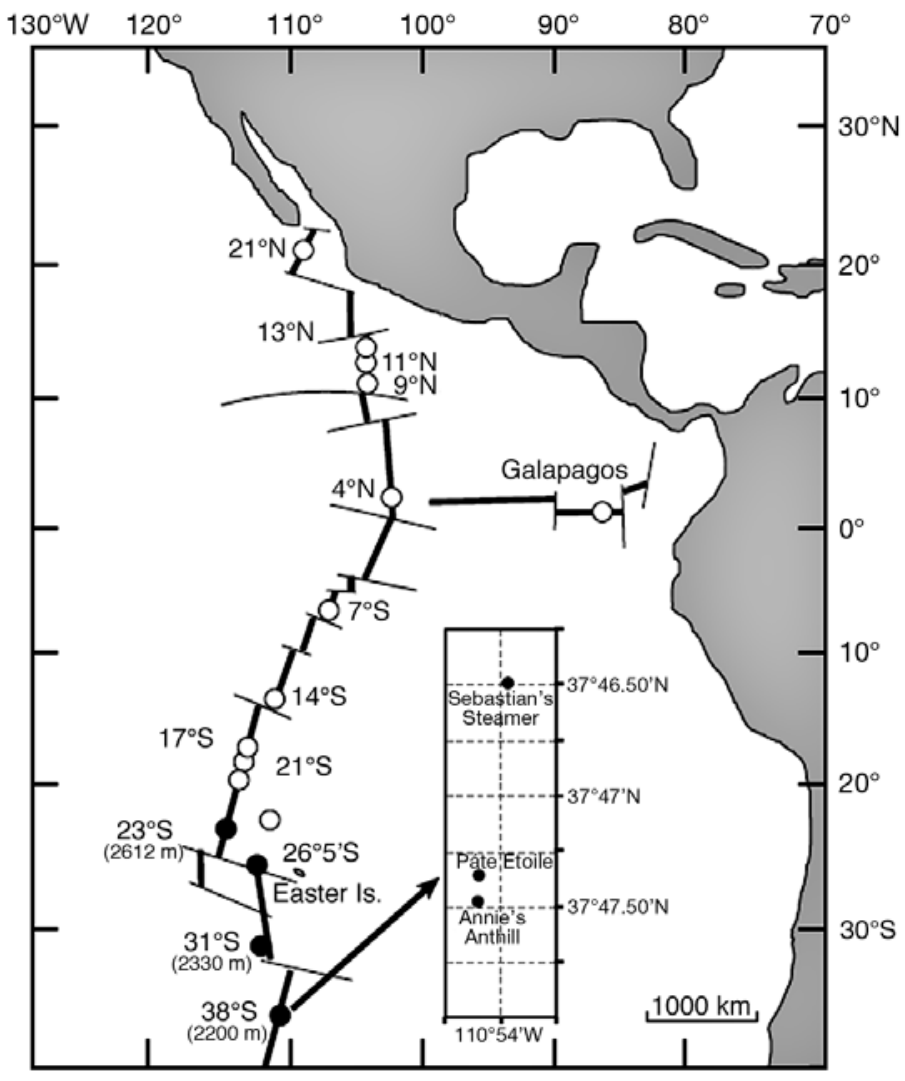

Fig. 1. East Pacific Rise and Pacific-Antarctic Ridge showing the hydrothermal vent sites, the vent sites visited during the PAR5 cruise (black dots) and the location of the sampling site (detail in rectangle) after Macpherson et al. 2005)

Sections of $5 \mu \mathrm{m}$ were stained with Mayer's haematoxylin and eosin. All sections were examined on an Olympus BX40 compound microscope, and for each individual, the Feret diameters (diameters of hypothetical circles of area equal to the objects measured) of at least 100 oocytes that had been sectioned through the nuclei were measured using the SigmaScan Pro 4 image analysis system. Feret diameter was used to standardise variations in oocyte shape. Images of oocytes were calibrated from measurements of a stage micrometer at identical magnification. Oocyte sizes were grouped in $10 \mu \mathrm{m}$ size classes and oocyte size-frequency diagrams were constructed for each individual.

Mean frequencies of each oocyte size class were plotted to visualize oocyte size-frequency distribution for the population of each species. Mean values for each oocyte size class were compared between 2 species using a non-parametric Mann-Whitney test with a significance level of $\alpha=0.05$. Non-parametric analysis was used because initial inspection of the data indicated that the variables were not normally distributed (Kolmogorov-Smirnov test of normality). 


\section{RESULTS}

\section{Sex ratio}

The sex ratio of Bythograea laubieri was significantly biased towards females, with 85 females and 25 males $\left(\chi^{2}=32.723,1 \mathrm{df}, \mathrm{p}<0.001\right)$. In contrast, the sex ratio of $B$. vrijenhoeki did not differ significantly from unity, with 63 females and 65 males $\left(\chi^{2}=0.031\right.$, $1 \mathrm{df}, \mathrm{p}>0.05)$.

\section{Ovarian structure}

Histological analysis indicated that, as in Bythograea thermydron from the East Pacific Rise (Perovich et al. 2003), the ovarian microstructures in B. laubieri and $B$. vrijenhoeki were similar to that of shallow water brachyuran crabs (Johnson 1980). The ovaries consist of several layers of developing oocytes enveloped by a thin gonad wall. Longitudinal strands of oogonia proliferate from the germinal epithelium and develop into previtellogenic oocytes. Previtellogenic oocytes contained little basophilic cytoplasm. Nuclei were large in relation to cell volume, and $>1$ nucleolus (usually 2 to 3 ) were frequently observed (Fig. 2). In both species, vitellogenesis began when the oocytes measured approximately $60 \mu \mathrm{m}$ in diameter. Vitellogenesis was identified by the presence of yolk granules appearing in the cytoplasm. Early vitellogenic oocytes (60 to $100 \mu \mathrm{m}$ diameter) had a basophilic granular cytoplasm. Vitellogenic (mature) oocytes (>100 $\mu \mathrm{m}$ diameter) had an acidophilic cytoplasm and were completely granular in appearance. The observed maximum oocyte size was $209 \mu \mathrm{m}$ in $B$. laubieri and $138 \mu \mathrm{m}$ in B. vrijenhoeki.

\section{Synchronicity of ovarian development}

Of the 20 females of each species used for histological analyses, 10 of Bythograea laubieri and 12 of $B$. vrijenhoeki showed evidence of recent release of their broods, including unhatched embryos, empty egg capsules and attachment stalks still present on the abdominal pleopods. None of the unhatched eggs showed signs of cleavage and could therefore have been unfertilized eggs or zygotes that did not develop. In either case, their size would have been similar to embryos in an early developmental stage. Unhatched eggs were approximately spherical in shape; the greatest and smallest mean diameters $( \pm \mathrm{SD})$ were, respectively, $0.50 \pm 0.03 \mathrm{~mm}$ and $0.46 \pm$ $0.04 \mathrm{in} \mathrm{B}$. laubieri, and $0.52 \pm 0.04 \mathrm{~mm}$ and $0.05 \pm$ $0.04 \mathrm{~mm}$ in $B$. vrijenhoeki. No ovigerous females were

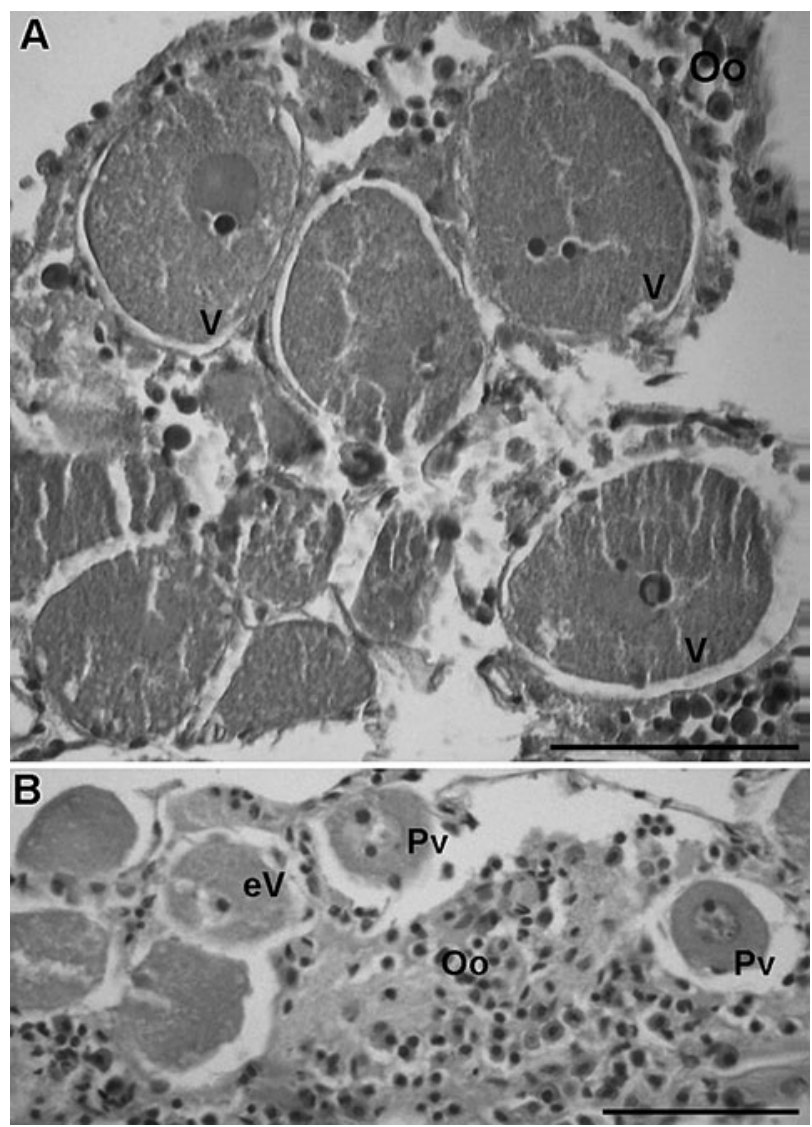

Fig. 2. Bythograea laubieri and B. vrijenhoeki. Light micrographs of histological sections through the ovary of (A) $B$. laubieri and (B) B. vrijenhoeki. eV: early vitellogenic; Oo: oogonia; Pv: previtellogenic; V: vitellogenic. Scale bar $=100 \mu \mathrm{m}$

found among the 148 females (85 of B. laubieri and 63 of $B$. vrijenhoeki) analysed.

Of the 40 females used for histological studies, we obtained good sections of the ovaries for 19 Bythograea laubieri and 16 Bythograea vrijenhoeki individuals. The oocyte size-frequency distributions of both species fit 3 patterns. The first pattern (previtellogenic) was characterized by a unimodal distribution of oogonia and previtellogenic oocytes $(<60 \mu \mathrm{m})$ (Fig. 3A-C and Fig. $4 \mathrm{~A}, \mathrm{~B})$; the second pattern (vitellogenic) was characterized by a unimodal distribution of previtellogenic oocytes and young vitellogenic oocytes $(<100 \mu \mathrm{m})$ (Fig. 3D-M and Fig. 4C-N); the third pattern was characterized by a bimodal distribution with a large cohort of mature oocytes $(>100 \mu \mathrm{m})$ and a smaller cohort of previtellogenic oocytes (Fig. 3N-S and Fig. 4O-P). Table 1 shows the numbers of females of both species in each of the 3 patterns. The presence of previtellogenic, vitellogenic and mature females at a single time suggests asynchronous oogenesis. 


\section{Inter-specific variability}

Bythograea laubieri has a greater mean oocyte diameter than B. vrijenhoeki (Fig. 5). This was supported by a Mann-Whitney test that indicated a significant difference in the mean oocyte size of the 2 species $(U=$ $2875242, \mathrm{p}<0.001)$. A chi-square test showed that the proportions of the 3 oocyte size-frequency distribution patterns (previtellogenic, vitellogenic and mature) were not significantly different between $B$. laubieri and B. vrijenhoeki $\left(\chi^{2}=0.343,2 \mathrm{df}, \mathrm{p}>0.05\right)$, suggesting that differences found in mean oocyte size were not due to a more advanced stage of gonad development in the entire population of $B$. laubieri.

\section{DISCUSSION}

The populations of Bythograea laubieri and B. vrijenhoeki collected at the Sebastian's Steamer vent site showed a sex ratio biased towards females and a 1:1 sex ratio, respectively. Perovich et al. (2003) observed a
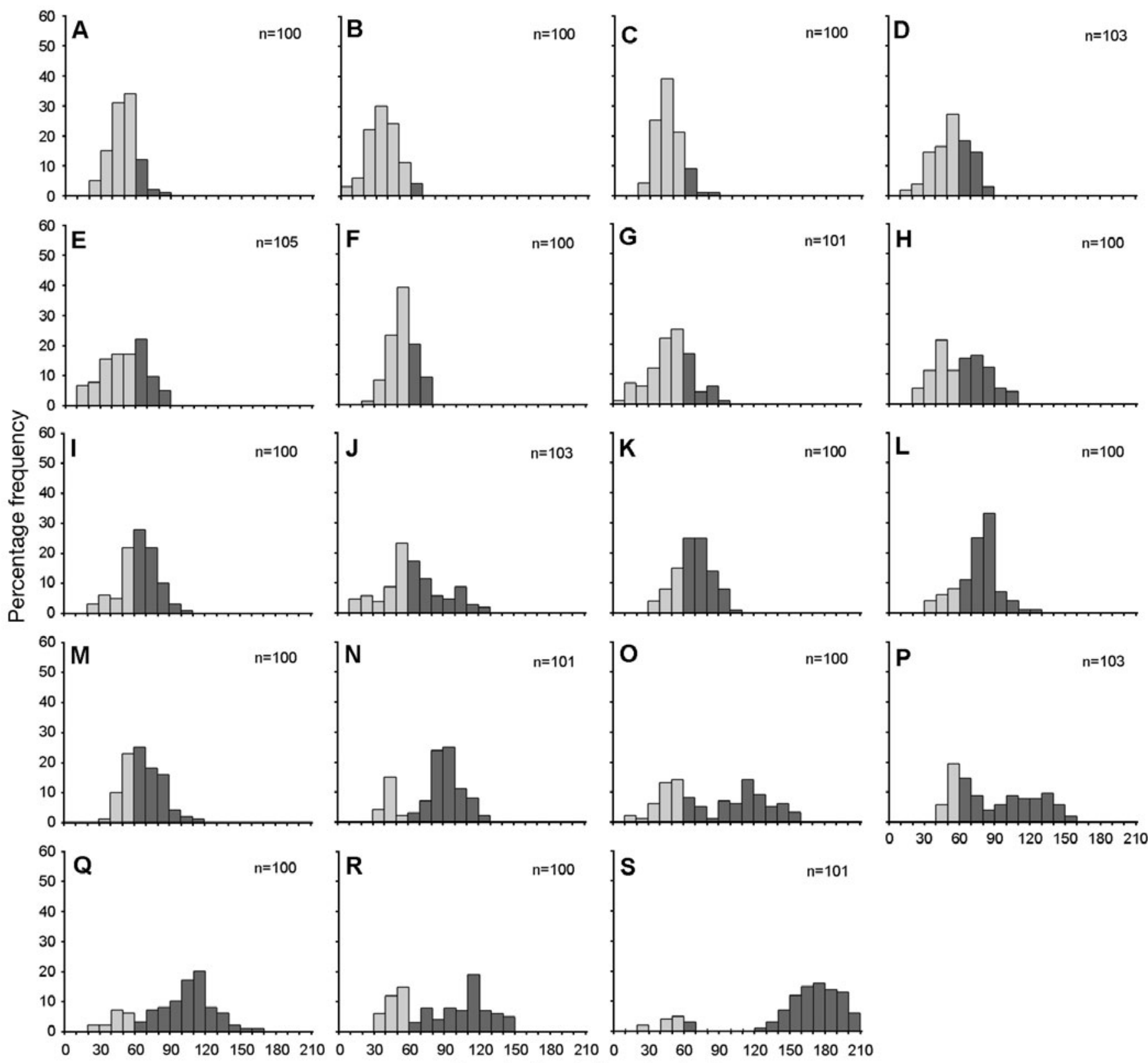

s

$n=101$

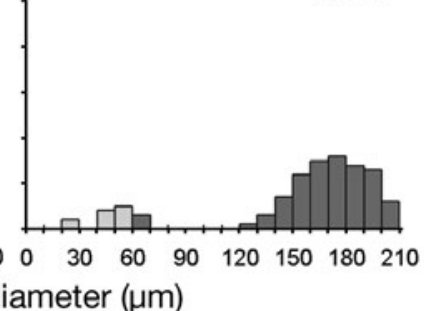

Fig. 3. Bythograea laubieri. Oocyte size-frequency distribution for each female. oogonia and pre-vitellogenic oocytes; $\square$ : vitellogenic oocytes 


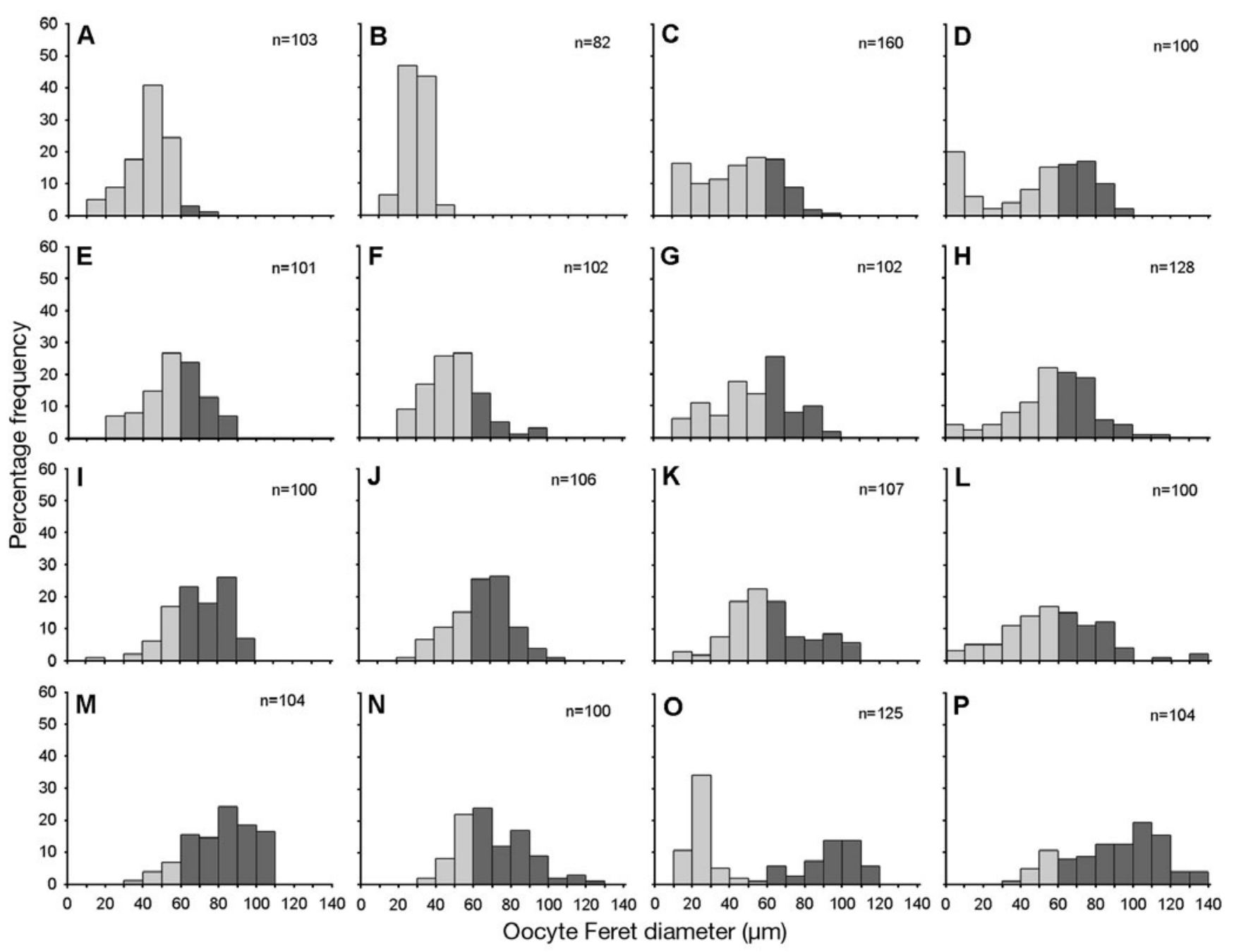

Fig. 4. Bythograea vrijenhoeki. Oocyte size-frequency distribution for each female. $\square$ : oogonia and pre-vitellogenic oocytes; $\square$ : vitellogenic oocytes

bias towards females in populations of $B$. thermydron collected from the periphery of vent sites, and suggested that females move to the periphery during the brooding period to avoid the hydrothermal fluids rich in sulphide and heavy metals that may be toxic to the embryos and larvae. Such behaviour has also been suggested for the caridean shrimp Rimicaris exoculata at vents on the Mid-Atlantic Ridge (Ramirez-Llodra et

Table 1. Bythograea laubieri and B. vrijenhoeki. Numbers of females in 3 categories of oocyte size-frequency distribution

\begin{tabular}{|lccc|}
\hline & Previtellogenic & Vitellogenic & Mature \\
\hline $\begin{array}{l}\text { B. laubieri } \\
(\mathrm{n}=19)\end{array}$ & 3 & 10 & 6 \\
$\begin{array}{l}\text { B. vrijenhoeki } \\
(\mathrm{n}=16)\end{array}$ & 2 & 12 & 2 \\
\hline
\end{tabular}

al. 2000). Although this behaviour may explain the absence of ovigerous females in the samples collected for the present study, it does not explain the bias towards females found in the population of Bythograea laubieri since the sample was collected in an active area of the vent field. Further studies are necessary to determine the processes causing sex ratio bias in $B$. laubieri, although this may be purely stochastic.

The reproductive traits of Bythograea laubieri and $B$. vrijenhoeki were expected to be similar to those of other members of the genus, as many reproductive and life history traits of decapod crustaceans from hydrothermal vents are thought to have strong phylogenetic constraints (Van Dover et al. 1985, Tyler \& Young 1999, Perovich et al. 2003).

The general gametogenic process of the 2 species studied was similar to that reported for Bythograea thermydron, but vitellogenic oocyte size $(>100 \mu \mathrm{m})$ 


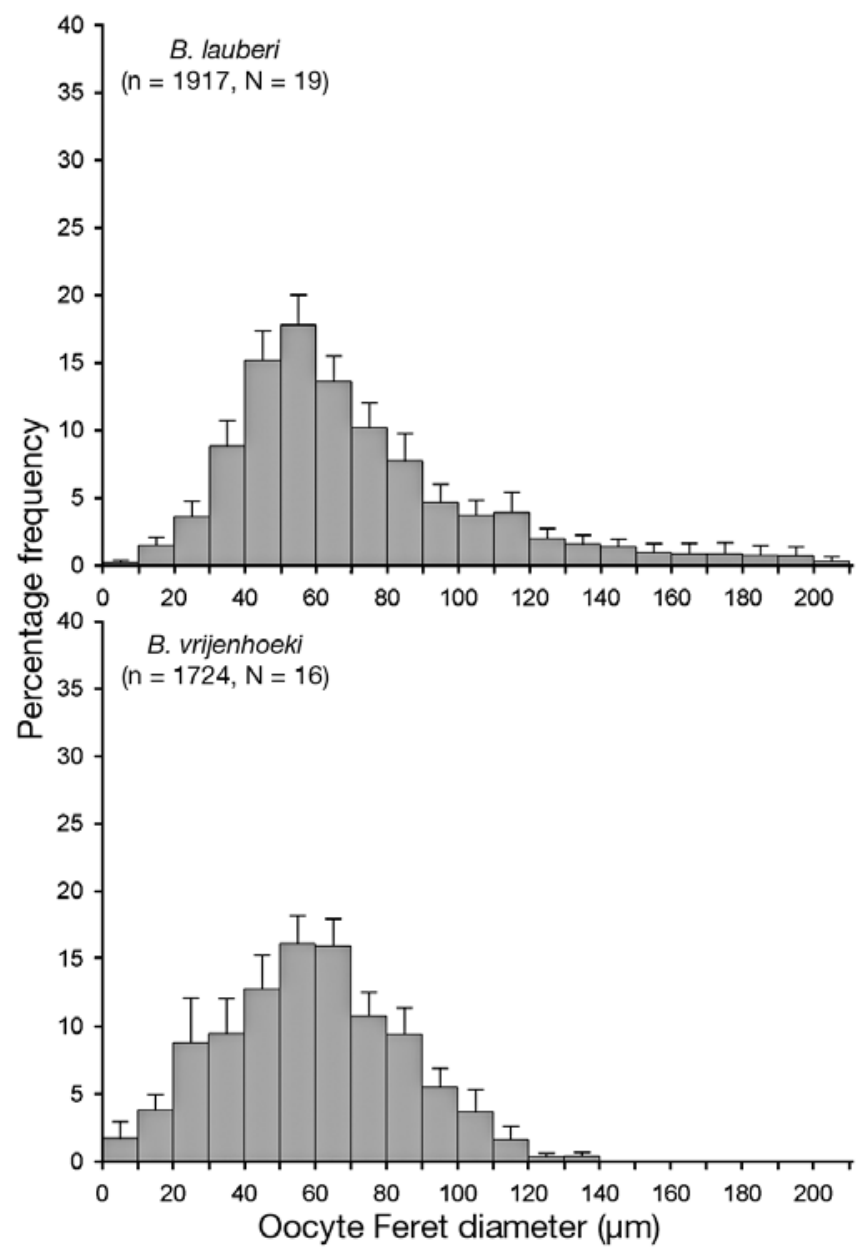

Fig. 5. Bythograea laubieri and B. vrijenhoeki. Mean sizefrequencies of oocytes. Means + SE. n: number of oocytes measured $; \mathrm{N}$ : number of individuals examined

and oocyte size at onset of vitellogenesis $(60 \mu \mathrm{m})$ were smaller than those reported by Perovich et al. (2003) ( 500 and $150 \mu \mathrm{m}$, respectively). Because histological processing can cause tissue shrinkage of up to $20 \%$, the differences in oocyte sizes could be a consequence of differing methodologies. However, even when accounting for these $20 \%$, vitellogenic oocyte size and oocyte size at onset of vitellogenesis in $B$. laubieri and $B$. vrijenhoeki would still be significantly smaller than in B. thermydron. Because the 3 species have a very similar morphology and size (Desbruyères et al. 2006), morphology can also be ruled out as a contributor to interspecific differences in maximum oocyte size.

At the individual level, the duration of oogenesis depends on the mechanisms of yolk deposition and on the number of egg cohorts developing at any given time (reviewed by Eckelbarger 1994). The mechanism of vitellogenesis is conserved in some groups, but in others selection can modify the timing and speed of gametogenesis to produce life cycles that reflect conditions of the environment in which the animal lives. Orton (1920) predicted that the reproduction of deepsea species would be continuous as a consequence of the constant temperature of their environment. Although the majority of non-vent deep-sea species have continuous asynchronous reproduction, there are examples of seasonal reproduction linked to variations in food supply at all latitudes and to depths reaching several thousand meters (reviewed by Young 2003). In situ primary production in chemosynthetic ecosystems in general, and in hydrothermal vents in particular, is not known to vary seasonally and is usually orders of magnitude greater than organic matter input from the photic zone. Seasonal variation in phytodetritus supply is therefore unlikely to influence the reproductive timing of species in these ecosystems directly through their energetics. However, species with planktotrophic larvae that disperse away from the chemosynthetic environment might still exhibit seasonal reproductive patterns. Seasonal reproduction at vents and seeps has been documented in bivalves (Le Pennec \& Beninger 1997, Lisin et al. 1997, Dixon et al. 2006, Tyler et al. 2007) and decapods (Perovich et al. 2003, Copley \& Young 2006). In the case of Bythograea thermydron, hatching of planktotrophic larvae coincides with the seasonal (spring and summer) phytoplankton blooms in surface waters (Perovich et al. 2003).

In contrast to Bythograea thermydron, females of $B$. laubieri and $B$. vrijenhoeki collected simultaneously from the Pacific-Antarctic Ridge contained oocytes in all stages of development, suggesting a lack of synchrony in reproduction for the population as a whole. The vent fields in the southern East Pacific Rise $\left(31^{\circ}\right.$ and $32^{\circ} \mathrm{S}$ ) and in the Pacific-Antarctic Ridge $\left(38^{\circ} \mathrm{S}\right)$ that have been explored so far are situated within the oligotrophic South Pacific Subtropical Gyre (SPSG). This gyre, located roughly between $20^{\circ}$ and $40^{\circ} \mathrm{S}$, is the most uniform and seasonally stable region of the open oceans; the nutrient-bearing waters are suppressed far below the euphotic zone, severely limiting phytoplankton production and yielding a very small flux of particulate organic carbon to the deep-sea floor (Tomczak \& Godfrey 1994). These features may therefore preclude possible cues for reproductive seasonality.

Guinot \& Hurtado (2003) showed a clear phylogenetic separation between 2 pairs of Bythograea species and placed $B$. thermydron and B. galapagensis in one group and $B$. laubieri and $B$. vrijenhoeki in another. The SPSG coincides with the distributional boundaries of these 2 groups. The B. thermydron/B.galapagensis clade is endemic to vents north of the gyre and the B. laubieri/B. vrijenhoeki clade is endemic to vents 
located within the gyre. Although the life history of $B$. galapagensis has not been investigated, the differences found between the B. laubieri/B. vrijenhoeki group and $B$. thermydron suggest that the SPSG can function as a dispersal barrier to bythograeid crabs. Attempts to understand the biogeography and gene flow between the insular hydrothermal vent ecosystems have tended to focus on the potential roles of topographical discontinuities (e.g. transform faults, microplates, bathymetric inflation, seamounts) and cross-axis currents as barriers to dispersal (Tyler et al. 2002, Van Dover et al. 2002). However, recent studies (Copley \& Young 2006, Copley et al. 2007) have suggested that links between surface productivity and ecological patterns in deep-sea chemosynthetic ecosystems, and features like oligotrophic gyres, might also influence the dispersal, gene flow and biogeography of some species.

\section{CONCLUSIONS}

The study of Bythograea laubieri and B. vrijenhoeki collected from the Sebastian's Steamer vent field at $38^{\circ} \mathrm{S}$ in Pacific-Antarctic Ridge showed that these 2 species have reproductive features that are phylogenetically conserved, but also specific characteristics that reflect the environmental condition in which they live. The ovary microstructure and general pattern of vitellogenesis is characteristic of brachyuran decapods, and our results suggest that, like other bythograeid species, ovigerous females of $B$. laubieri and $B$. vrijenhoeki gather outside of the direct influence of the vent field. On the other hand, and in contrast to B. thermydron, these 2 sister species seem to lack synchrony in gonad development. These differences in the reproductive pattern of species belonging to the same genus suggest that the timing of gametogenesis in bythograeid crabs may not be phylogenetically constrained.

Although the nature of the cue synchronizing the gametogenic pattern of some vent species remains unknown, previous studies have linked the synchrony of reproduction in Bythograea thermydron with the seasonal formation of phytoplankton blooms in surface waters. The geographical distribution of $B$. laubieri and $B$. vrijenhoeki falls within the boundaries of the SPSG, where the absence of blooms and constant oligotrophy may preclude environmental cues for seasonal reproduction. This oceanographic feature may also function as a dispersal barrier determining the biogeographic patterns of Bythograea species.

Acknowledgements. We thank the co-chief scientists of the PAR5 cruise R. Vrijenhoek and C. Van Dover for the invitation to participate in the cruise, as well as the captain and crew of the RV 'Atlantis' and deep-submersible 'Alvin' for assistance in collecting specimens. We also thank M. Segonzac for collecting the specimens and for the species identification. A.H. was supported by a FCT grant (SFRH/BPD/22383/2005) that is gratefully acknowledged.

\section{LITERATURE CITED}

Bennett JT, Turekian KK (1984) Radiometric ages of brachyuran crabs from the Galapagos Spreading-Center hydrothermal vent field. Limnol Oceanogr 29:1088-1091

Childress JJ, Fisher CR (1992) The biology of hydrothermal vent animals: physiology, biochemistry, and autotrophic symbioses. Oceanogr Mar Biol Annu Rev 30:337-441

> Copley JTP, Young CM (2006) Seasonality and zonation in the reproductive biology and population structure of the shrimp Alvinocaris stactophila (Caridea: Alvinocarididae) at a Louisiana Slope cold seep. Mar Ecol Prog Ser 315: 199-209

> Copley JTP, Jorgensen PBK, Sohnt RA (2007) Assessment of decadal-scale ecological change at a deep Mid-Atlantic hydrothermal vent and reproductive time-series in the shrimp Rimicaris exoculata. J Mar Biol Assoc UK 87: 859-867

Desbruyères D, Segonzac M, Bright M (eds) (2006) Handbook of deep-sea hydrothermal vent fauna, 2nd edn. Denisia 18, Landesmuseen, Linz

Dixon DR, Lowe DM, Miller PI, Villemin GR, Colaço A, Serrão-Santos R, Dixon LRJ (2006) Evidence of seasonal reproduction in the Atlantic vent mussel Bathymodiolus azoricus, and an apparent link with the timing of photosynthetic primary production. J Mar Biol Assoc UK 86: 1363-1371

Eckelbarger KJ (1994) Diversity of metazoan ovaries and vitellogenic mechanims: implications for life history theory. Proc Biol Soc Wash 107:193-218

Epifanio CE, Perovich GM, Dittel AI, Cary SC (1999) Development and behavior of megalopa larvae and juveniles of the hydrothermal vent crab Bythograea thermydron. Mar Ecol Prog Ser 185:147-154

Guinot D, Hurtado LA (2003) Two new species of hydrothermal vent crabs of the genus Bythograea from the southern East Pacific Rise and from the Galapagos Rift (Crustacea Decapoda Brachyura Bythograeidae). C R Biol 326: 423-439

Guinot D, Segonzac M (1997) Description of a new hydrothermal crab of the genus Bythograea (Crustacea, Decapoda, Brachyura) and remarks on the Bythograeidae of the East Pacific Rise. Zoosystema 19:121-149

Johnson PT (1980) The histology of the blue crab, Callinectes sapidus. Praeger Publishers, New York

Le Pennec M, Beninger PG (1997) Ultrastructural characteristics of spermatogenesis in three species of deep-sea hydrothermal vent mytilids. Can J Zool 75:308-316

Lisin SE, Hannan EE, Kochevar RE, Harrold C, Barry JP (1997) Temporal variation in gametogenic cycles of vesicomyid clams. Invertebr Reprod Dev 31:307-318

Little CTS, Vrijenhoek RC (2003) Are hydrothermal vent animals living fossils? Trends Ecol Evol 18:582-588

Macpherson E, Jones W, Segonzac M (2005) A new squat lobster family of Galatheoidea (Crustacea, Decapoda, Anomura) from the hydrothermal vents of the PacificAntarctic Ridge. Zoosystema 27:709-723

Martin JW, Dittel AI (2007) The megalopa stage of the hydrothermal vent crab genus Bythograea (Crustacea, Decapoda, Bythograeidae). Zoosystema 29:365-379 
Martin JW, Haney TA (2005) Decapod crustaceans from hydrothermal vents and cold seeps: a review through 2005. Zool J Linn Soc 145:445-522

Mickel TJ, Childress JJ (1982) Effects of temperature, pressure, and oxygen concentration on the oxygen-consumption rate of the hydrothermal vent crab Bythograea thermydron (Brachyura). Physiol Zool 55:199-207

Orton JH (1920) Sea temperature, breeding and distribution in marine animals. J Mar Biol Assoc UK 12:339-366

Perovich GM, Epifanio CE, Dittel AI, Tyler PA (2003) Spatial and temporal patterns in development of eggs in the vent crab Bythograea thermydron. Mar Ecol Prog Ser 251: 211-220

Ramirez-Llodra E, Tyler PA, Copley JTP (2000) Reproductive biology of three caridean shrimp, Rimicaris exoculata, Chorocais chacei and Mirocaris fortunata (Caridea: Decapoda), from hydrothermal vents. J Mar Biol Assoc UK 80: 473-484

Sanders NK, Childress JJ (1985) Unusual oxygen bindingproperties in the blood of the deep-sea hydrothermal vent crab Bythograea thermydron. Am Zool 25:A119

Sanders NK, Childress JJ (1992) Specific effects of thiosulfate and L-lactate on the hemocyanin-O2 affinity in a brachyuran hydrothermal vent crab. Mar Biol 113:175-180

Tomczak M, Godfrey JS (1994) Regional oceanography: an introduction. Pergamon, London

Tunnicliffe V, McArthur AG, McHugh D (1998) A biogeographical perpective of the deep-sea hydrothermal vent fauna. Adv Mar Biol 34:354-442

Tunnicliffe V, Juniper SK, Sibuet M (2003) Reducing environments of the deep-sea floor. In: Tyler PA (ed) Ecosystems of the world: the deep-sea. Elsevier, Amsterdam, p 81-110

Editorial responsibility: Don Levitan, Tallahassee, Florida, USA
Tyler PA, Young CM (1999) Reproduction and dispersal at vents and cold seeps. J Mar Biol Assoc UK 79:193-208

Tyler PA, German CR, Ramirez-Llodra E, Van Dover CL (2002) Understanding the biogeography of chemosynthetic ecosystems. Oceanol Acta 25:227-241

Tyler P, Young CM, Dolan E, Arellano SM, Brooke SD, Baker $M$ (2007) Gametogenic periodicity in the chemosynthetic cold-seep mussel 'Bathymodiolus' childressi. Mar Biol 150:829-840

Van Dover CL (2000) The ecology of deep-sea hydrothermal vents. Princeton University Press, Princeton, NJ

Van Dover CL, Factor JR, Williams AB, Berg CJ Jr (1985) Reproductive patterns of decapod crustaceans from hydrothermal vents. Proc Biol Soc Wash 6:223-227

Van Dover CL, Williams AB, Factor JR (1984) The first zoeal stage of a hydrothermal vent crab (Decapoda: Brachyura: Bythograeidae). Proc Biol Soc Wash 97:413-418

Van Dover CL, Franks PJS, Ballard RD (1987) Prediction of hydrothermal vent locations from distributions of brachyuran crabs. Limnol Oceanogr 32:1006-1010

Van Dover CL, German CR, Speer KG, Parson LM, Vrijenhoek RC (2002) Evolution and biogeography of deep-sea vent and seep invertebrates. Science 295:1253-1257

Vetter RD, Wells ME, Kurtsman AL, Somero GN (1987) Sulfide detoxification by the hydrothermal vent crab Bythograea thermydron and other decapod crustaceans. Physiol Zool 60:121-137

Williams A (1980) A new crab family from the vicinity of submarine thermal vents of the Galapagos rift (Crustacea: Decapoda: Brachyura). Proc Biol Soc Wash 93:443-472

Young CM (2003) Reproduction, development and life-history traits. In: Tyler PA (ed) Ecosystems of the world: the deepsea. Elsevier, Amsterdam, 381-426

Submitted: April 9, 2008; Accepted: November 21, 2008 Proofs received from author(s): March 2, 2009 